www.mdpi.com/journal/socsci

Article

\title{
Sustainable Paper Consumption: Exploring Behavioral Factors
}

\section{Bertha Maya Sopha}

Industrial Engineering Programme, Department of Mechanical and Industrial Engineering, Gadjah Mada University (UGM), Yogyakarta 55281, Indonesia; E-Mail: bertha_sopha@ugm.ac.id; Tel.: +62-274-521673; Fax: +62-274-521673

Received: 11 September 2013; in revised form: 23 October 2013 / Accepted: 30 October 2013 / Published: 8 November 2013

\begin{abstract}
Although the paperless office (PLO) management system has been established with the goal of paper usage reduction, demand for paper has still showed an uptrend over the years. Given the substantial pressure on forest ecosystems due to a continued increase of paper consumption, understanding the behavioral aspects of paper consumption is, therefore, required. This present paper aims at exploring the factors underlying paper consumption behavior. Empirical data was acquired through a survey of 266 Indonesian students, involving both undergraduate and postgraduate students. A theoretical model, based on the Comprehensive Action Determination Model (CADM), was tested against the empirical data. It was found that the model received reasonable support from the data. Results indicate that reducing paper consumption behavior is strongly influenced by habit and, marginally significant, by intention. Furthermore, habit formation is influenced by both normative processes and situational influences. The results, to some extent, explain the PLO paradox in a way that the PLO program should have focused on breaking the habit of paper usage instead of promoting the benefits of PLO. Introducing a paper quota and rationing (fee) to new students, as the main target, is a potential policy intervention implied from the results.
\end{abstract}

Keywords: behavioral factors; paper consumption; Indonesian students; PLO paradox

\section{Introduction}

Technology improvements, i.e., increased production efficiency, do not suffice to considerably reduce the use of natural resources. An efficiency paradox, known as Jevons paradox, or rebound effect, defines that an increase in efficiency, as one may not expect, tends to, rather than decrease, 
increase the use of natural resources due to the increase in the consumption level of those resources. This phenomenon has been widely observed in energy-related behavior, i.e., energy-saving investment [1] and space heating [2]. It seems that this typical paradox also applies to paper consumption as was evidenced that the introduction of e-mail into an organization caused on average, unexpectedly, a $40 \%$ increase in paper consumption [3]. Hence, this phenomenon was called the paperless office paradox (PLO paradox), wherein the development of a substitute of papers (i.e., computers, emails, internet, PDA, etc.) resulted in an increase of paper consumption [4].

The PLO paradox imposes the importance of addressing the consumption aspect so that the efficiency gain is not paid off, or back paid, by more consumption. Midden et al. [5] highlight the need of behavioral changes to address a case where efficiency gains resulted from energy-efficient technology tend to be overtaken by consumption growth. Understanding the behavioral aspects of paper consumption is, therefore, of significance.

Behavioral literature has identified a wide range activity, which is considered as pro-environmental behavior, such as recycling behavior, driving habits, energy-saving behavior, environmental citizenship/activism, and policy support [6]. It is interesting, however, that lack of literature, according to the best knowledge of the author, discusses paper consumption behavior. From an environmental impact point of view, paper consumption leads to a significant impact on material use, as papers, which are usually made of wood fiber, put a substantial pressure on natural forests. For instance, in the Indonesian context, paper consumption reached 5.6 million tons in 2005, which required 25.2 million $\mathrm{m}^{3}$ of logs, to produce one ton of pulp required $4.5 \mathrm{~m}^{3}$ of $\operatorname{logs}$ [7]. Assuming that conversion of potential logs to forest area has an average of $80 \mathrm{~m}^{3}$ per hectare, then to meet the raw material needs of the pulp industry, about 315,000 hectares of natural forest should be cut down. Natural forest destroyed by clear-cutting will be growing, along with the increasing capacity of the pulp and paper industry. Although forest plantation is obliged by the government, the realization of $20 \%$ is too slow to catch up with the increase of the requirements. Indonesian deforestation in the period 1985-1998 was recorded at not less than 1.6 million hectares per year [8].

Indonesian paper consumption per capita was historically showing an increasing trend. In 1996, consumption of paper in Indonesia was about 3.1 million tons and increased continuously since then [9]. Continued increase of paper consumption was mainly triggered by the growing demand for paper. Given the steady increase of paper consumption, the paperless office management system has been promoted and implemented, particularly in universities and government institutions, in the late 1990 s in order to reduce paper use. It was presumed that using information technology is more environmentally-friendly than using paper due to both, less natural resource usage, and less emissions. The assumption was eventually proven by Toffel and Horvard [10] who compared the environmental impacts of reading news from wireless and wired technology, such as PDAs, and that from newspapers using the life-cycle approach. It was demonstrated that reading news from wireless and wired technology associates to lower $\mathrm{CO}_{2}, \mathrm{~N}_{2} \mathrm{O}$, and $\mathrm{SO}_{2}$ emissions in comparison to reading news from newspapers [10]. However, despite the paperless office program, paper consumption increased steadily to 5.6 million tons, which was almost double the last 10 years. It is projected that, due to a steady increase of paper demand, paper production would reach 13 million tons by the end of 2013 [11]. PLO programs are voluntary, at least for now, so that the effectiveness of the program is dependent on individual behavior. 
A question remains to which factors actually determine paper consumption behavior, and which intervention is effective to reduce paper consumption at end-users. To address those questions, it is indeed required understandings on contextual elements, psychological factors underlying behaviors, and their interplay with contextual factors [12]. Psychological models study behavioral changes by systematically examining main factors underlying behavior, assessing intervention to change the relevant behaviors and their determinants, and further evaluating the effects of interventions [13]. Research related to resource management may therefore benefit from psychological models because the models address internal decision-making process, which embraces cognitive, habit, and contextual constraints. Those internal factors, furthermore, generate insights which can be fairly translated into tailored policy intervention. Potential interventions derived from psychological models could be either aimed to influence underlying behavioral determinants (known as antecedent strategies), i.e., commitment, goal setting, information, modeling, or based on consequence which influence behavior (consequence strategies), i.e., feedback, rewards [14]. This study, therefore, aims at understanding underlying factors explaining paper usage behavior. It is expected that results of this study would help to identify core determinants of paper consumption, as well as potential interventions either to alleviate barriers or to facilitate the behavior. This research, thus, borrows a psychological model due to its feature of incorporating various internal behavioral aspects into one framework to promote behavioral changes in paper consumption.

Psychological models have actually been widely used in energy studies, particularly when the assumption of rational behavior fails to explain non-adoption of beneficial options. Some literatures indicated that other factors such as support from peers, resistance, preferences, etc., were found to be influential. Moreover, customers do not perform consistently rational behavior as of lots of cognitive efforts (collect, analyze, and evaluate information about all possible alternatives before making a decision), rather, they usually use wide range of rules or heuristics, such as satisfying (choosing the alternative which meets a utility threshold), recognition (choosing the alternative which was familiar), etc. [15]. Psychological models are found to be useful to address bounded rational behavior, when other factors such as heuristics, peer pressure, values, and habit, may play roles.

With respect to pro-environmental behavior, the behavior can, in general, be categorized into two categories; efficiency behavior and curtailment behavior [16]. Efficiency behavior refers to an investment made to gain a reduction over time. In energy-related domain, some examples could be identified such as light-bulb purchasing [17], green electricity adoption [18], and high-cost energy investment, e.g., a heating system [19,20]. Curtailment behavior is related to usage. Examples are electricity-saving behavior [21,22], transportation mode choice/car use [23-25], fuel consumption [26], and fuel switching [27]. According to the categorization, paper consumption behavior could, thus, be considered as curtailment behavior.

The present paper is structured as follows: Section 2 describes a theoretical framework for explaining paper consumption behavior, followed by a method in Section 3 consisting of a sampling method and questionnaire design. Results are presented in Section 4 before closing with discussions in Section 5. 


\section{The Theoretical Framework}

Pro-environmental behavior have long been studied in economics, psychology, and sociology. Several studies have shown that different types of behavior are influenced by different motivational variables and thus related to different types of explanatory variables [28]. A number of psychological models exist in literature such as Theory of Planned Behavior (TPB) [29], Norm Activation Model (NAM) [30], Value Belief Norm (VBN) [31], and the Triandis model [32], to name a few. As those theories focus on one aspect, and underestimate the other aspects, consequently, one model that fits to one specific domain might not be applicable to another domain. For instance, TPB focuses on intention and neglects personal norms, while NAM focuses on personal norms but underestimates the role of situational constraint. Meanwhile, habit concept addresses both intention and habit, but overlooking the impact of situational constraints and normative process. Inspired by the need of a more representative multi-determination model, Klöckner \& Blöbaum [33] proposed an integrated model named as the Comprehensive Action Determination Model (CADM), which combines features of the aforesaid models. CADM incorporates intentional, normative, situational, and habitual influences in explaining pro-environmental behavior, and was successfully applied to travel mode choice [33] and energy-efficient investment behavior [19].

The CADM model, thus, allows multi-determination of environmental behavior. The model is particularly useful when a domain, such as paper consumption behavior, is still under-explored. Due to the exploratory nature of this present study, the CADM is hence applied.

The core assumption of CADM is that behavior is directly predicted by intention, perceived behavioral control, and habit. Following the TPB, an intention (INT) refers to the feeling of being ready and willing to perform a behavior - in this case paper consumption, whereas perceived behavioral control (PBC) corresponds to his/her perceived ability to perform the behavior. Habit (HAB) refers to both behavioral routines and behavioral automaticity. On the second level, in line with the TPB, intentional process is generated from attitude toward the behavior (ATT), perceived behavioral control (PBC), and social norms (SN). Attitude regards person's evaluation on the behavior, whereas social norms indicate the influence of relevant other people on the behavior (such as peer pressure). In addition, Personal Norms (PN), which reflect to the feeling of moral obligation according to person's values, also influence intention directly as indicated by some literatures, e.g., [34]. Normative processes (i.e., social norms, personal norms) do not influence behavior directly, but are mediated by intentional and habitual processes. Personal norms, themselves, are considered stable, yet $\mathrm{PBC}$ could impact $\mathrm{PN}$ in the long terms (i.e., situational influences deactivate personal norms if behavior, which is in line with norms, is not easy to do).

Based on CADM, a theoretical framework explaining the behavior of paper consumption is proposed and illustrated in Figure 1. Paper consumption behavior is hypothesized to be predicted by individual's intention, perceived ability to reduce paper usage, as well as, the degree to which reducing paper usage is habitual. As paper consumption is considered as a day-to-day decision, which does not require much of cognitive effort, the influence of habit is expected to be stronger than the intention. Within intentional process, the intention is predicted by the personal evaluation on reducing paper consumption, perceived ability, the feeling of personal obligations, and social pressure to reduce paper usage. In CADM, situational influences consist of both subjective and objective constraints. Objective 
constraint is however not represented in this study. As this study focuses on how the perceptions of control differ from the objective control, the situational influence is, hence, only predicted by PBC. The situational influences and the evaluation of behavioral outcomes shape whether reducing paper consumption is possible to do according to personal norms. If reducing paper consumption, which is in line with norms, is not difficult to do, then a habit is generated so that situational influences impact the habit indirectly through personal norms. Being pro-environmental behavior, the paper consumption behavior is expected to be influenced by both social norms and personal norms (normative process). The influences are, however, indirectly, mediated by intentional or habitual process. Within the normative process, the feeling of personal obligation to reduce paper is influenced by pressure from relevant other people.

Figure 1. The tested theoretical framework to explain reducing paper consumption behavior. Standardized regression weights are displayed $(N=266)$.

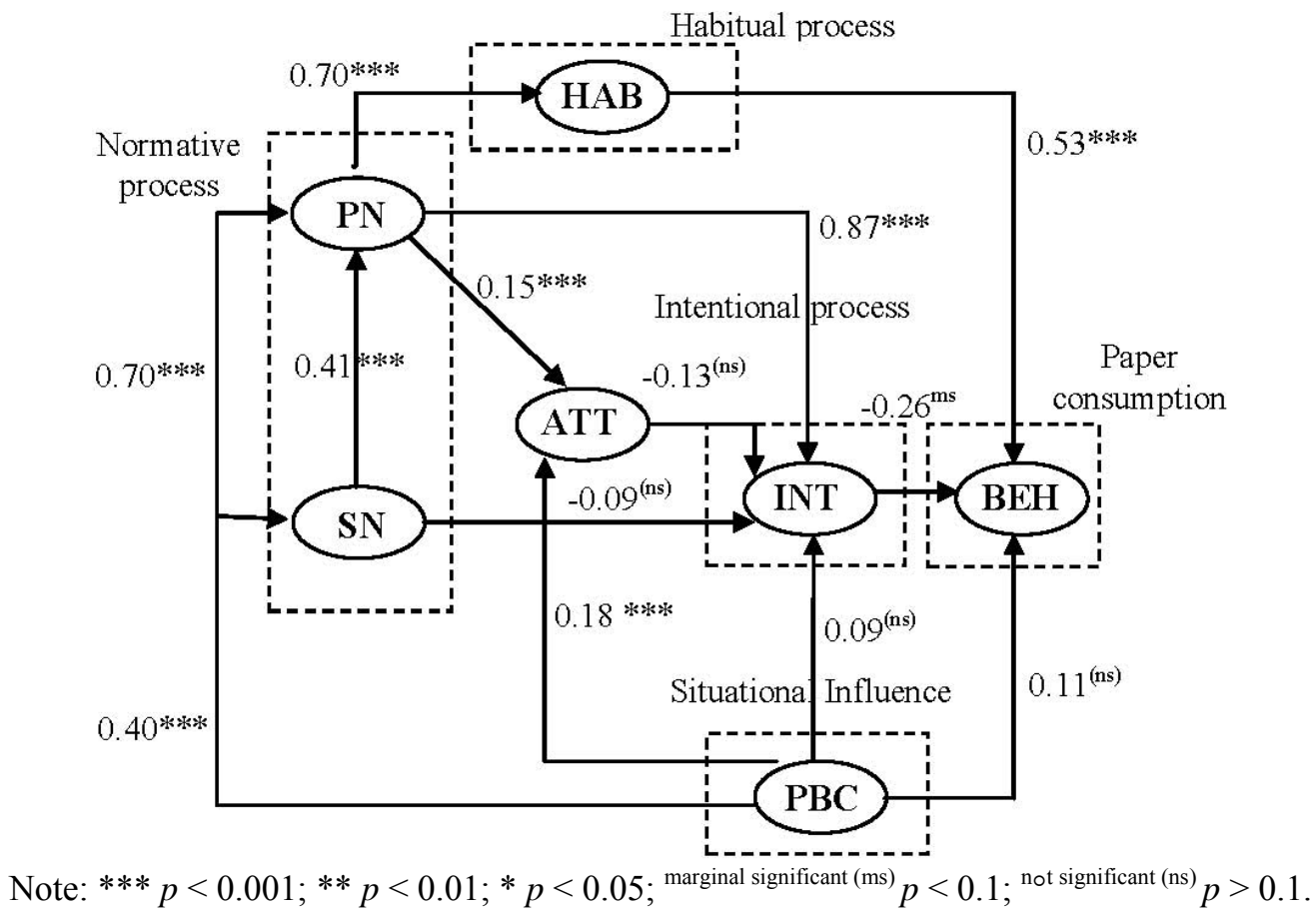

It is also worth mentioning that the relations specified in psychological models are not always supported by empirical data. Literature found gaps, which occur between behavior and intention [35], intention and attitude [36], and behavior and values [37]. With respect to a behavior-intention gap, a field experiment in travel mode choice, conducted by Verplanken et al. [35], demonstrated that the relation between intention and behavior existed only when habit was weak, and on the contrary. The study furthermore examined that providing information would not be an effective option because those with strong habits acquired less information. Moreover, the study suggested although external incentives may increase the intention, habits set boundary conditions for intention to be translated to behavior. The study is supported by some literature, for example, Ajzen [38] evidenced that the impact of habit vanished when intentions are strong and well-formed, and Limayem et al. [39] demonstrated that habit limits the predictive power of intention of using information system. Behavior-intention gaps 
could also be found in various domains such as physical exercise, dietary behavior, and purchasing behavior. In addition to habit, self-efficacy, and action control (perceived self-regulatory process), situational constraints may explain the presence of behavior-intention gap. Gaps also exist between intention and attitude as explored, by Vermeir and Verbeke [36] in food consumption. The study indicated that perceived availability explains low intention to buy despite positive attitude, and, on the reverse side, that social pressure explains high intention despite negative attitude. Another type of gap, a behavior-value gap, is also observed in literature and some factors (i.e., lack of knowledge, lack of support, lack of time, lack of money, and lack of control over decision-making) explain the gap [40].

\section{Method}

An empirical data for assessing various components in the paper consumption behavior was collected through a survey, which was conducted in 2012. The unit analysis in this study is an individual. The theoretical model was then tested against the empirical data with a Structural Equation Model (SEM). The statistical packages of Statistical Product and Service Solution (SPSS) and Analysis of Moment Structures (AMOS) were used for analysis.

\subsection{Sample}

This present study was based on random sampling of 266 students at Industrial Engineering Programme, Gadjah Mada University, consisting of both undergraduate and graduate students from various entry-years. Since the greatest demand for paper type is printing and writing paper which are account for $60 \%$ of the paper production [9], student respondents were thus selected as it is presumed that students are prone to use paper intensively.

Each student received a questionnaire and participation in this study was voluntary. In the end, 279 out of 386 sent questionnaires were returned so that a response rate of $72 \%$ was obtained. Some respondents did not answer the all questions so that the response rate varies for each question. Respondents with missing values in exogenous variables had to be excluded from the study so that the final analysis was based on a sample of 266 participants. Table 1 illustrates the profile of the respondents.

Table 1. Respondent Profiles $(N=266)$.

\begin{tabular}{lcc}
\hline Attribute & & \\
\hline Age & Mean (year) & SD (year) \\
& 19.9 & 2.2 \\
\hline Gender & $\boldsymbol{N}$ & Percentage (\%) \\
Male & 141 & 53 \\
Female & 125 & 47 \\
Education Level & & \\
Undergraduate & 244 & 92.7 \\
$1^{\text {st }}$ year & 1 & 0.4 \\
$2^{\text {nd }}$ year & 115 & 43.2 \\
$3^{\text {rd }}$ year and above & 128 & 48.1 \\
Graduate & 22 & 8.3 \\
$1^{\text {st }}$ year & 10 & 3.8 \\
$2^{\text {nd }}$ year & 12 & 4.5 \\
\hline
\end{tabular}


To test if the gender distribution of the random sample deviated significantly from the gender distribution of all students in the university, a Chi-square test was conducted, and resulted in insignificant differences $\left(C h i^{2}=0.160, d f=1, p=0.689\right)$. This means that the composition of sample, with respect to gender, is representative of the student population in the university. The same test was also conducted for the distribution of education level. However, due to unavailability data in university level, department level data was used. An insignificant difference resulted from a Chi-square test $\left(C h i^{2}=0.050, d f=1, p=0.823\right)$ implies that the sample is able to represent student population with respect to education level.

\subsection{Questionnaire}

The questionnaire consists of the aim of study, questions related to socio-demographics (i.e., age, gender, education level, and entry-years), paper consumption behavior, and psychological variables (i.e., behavior (BEH), intention (INT), attitude (ATT), perceived behavioral control (PBC), habit $(\mathrm{HAB})$, personal norm $(\mathrm{PN})$, and social norms $(\mathrm{SN})$ ). All variables but behavior were each measured with two items. These measures were adopted, based on a review of 90 psychological literatures, focusing on indicators of determinants of pro-environmental behavior [41]. The most reliable, and the most widely-used measures, in psychological literatures were adopted, adjusted to the context of this present study, and then translated to Indonesian.

The dependent behavioral variable of this study is behavior to reduce paper consumption which was operationalized using "How often do you X?", in which X consists of three items related to the use of paper, only if needed, the use of both sides of papers when printing/writing, and the choice of electronic devices over papers for reading and writing. The measure has an acceptable reliability (cronbach's alpha $=0.61$ ).

INT was measured with keywords of "I intent to..." and "I would..." (cronbach's alpha $=0.73$ ). ATT was measured using semantic differential of bad-good and unpleasant-pleasant regarding reducing paper consumption (cronbach's alpha $=0.50$ ). "It would be easy to..." and "For me, reducing my use for paper is possible" were used to operationalize PBC, and both items result in cronbach's alpha of 0.53 . PN items which, have good reliability (cronbach's alpha $=0.74$ ), were measured using "I feel personally obliged to..." and "Due to my values/principles, I feel obliged to...". SN was operationalized with two items (cronbach's alpha =0.74); "People who are important to me think that I should..." and "My colleagues/friends think that I should...". HAB was measured by subjective judgment to what extent reducing paper consumption is considered as a routine/automatic behavior (cronbach's alpha $=0.66$ ). The answering scales in the present study were also used in accordance with [30], who found that the most widely used scale in psychological literature was a 5-point Likert scale $(1=$ totally disagree and $5=$ totally agree $)$.

Prior to data collection, a pilot study consisting of 20 respondents was conducted to test and refine the questionnaire. Factor analysis (regrouping of items) was not conducted due to the confirmatory nature of the study. 


\section{Results}

Results of the structural equation model are displayed in Table 2 and Figure 1. The antecedents of paper usage behavior, although not all factors significant, in overall, demonstrate moderately explanatory power of the behavior among Indonesian students. The proposed model is able to explain $36 \%$ of variance in the variable underlying paper consumption behavior.

Table 2. Unstandardized and standardized regression weights, standard errors, p-levels, and estimated $\mathrm{R}^{2}$ of the structural model $(N=266)$.

\begin{tabular}{|c|c|c|c|c|c|}
\hline & B & SE & Beta & $\mathbf{p}$ & $\mathbf{R}^{2}$ \\
\hline $\mathrm{BEH} \leftarrow \mathrm{INT}$ & -0.262 & 0.149 & -0.287 & $0.077^{\mathrm{ms}}$ & \\
\hline $\mathrm{BEH} \leftarrow \mathrm{HAB}$ & 0.531 & 0.155 & 0.678 & $<0.001 * * *$ & \\
\hline $\mathrm{BEH} \leftarrow \mathrm{PBC}$ & 0.106 & 0.111 & 0.128 & 0.341 & \\
\hline BEH & & & & & 0.358 \\
\hline $\mathrm{INT} \leftarrow \mathrm{ATT}$ & -0.132 & 0.246 & -0.056 & 0.591 & \\
\hline $\mathrm{INT} \leftarrow \mathrm{PBC}$ & 0.094 & 0.135 & 0.104 & 0.487 & \\
\hline $\mathrm{INT} \leftarrow \mathrm{SN}$ & -0.093 & 0.090 & -0.107 & 0.301 & \\
\hline $\mathrm{INT} \leftarrow \mathrm{PN}$ & 0.867 & 0.178 & 0.939 & $<0.001 * * *$ & \\
\hline INT & & & & & 0.829 \\
\hline $\mathrm{ATT} \Leftarrow \mathrm{PN}$ & 0.147 & 0.051 & 0.374 & $0.004 * *$ & \\
\hline $\mathrm{ATT} \Leftarrow \mathrm{PBC}$ & 0.176 & 0.062 & 0.456 & $0.004 * *$ & \\
\hline ATT & & & & & \\
\hline $\mathrm{HAB} \leftarrow \mathrm{PN}$ & 0.702 & 0.094 & 0.653 & $<0.001 * * *$ & \\
\hline $\mathrm{HAB}$ & & & & & 0.426 \\
\hline $\mathrm{PN} \leftarrow \mathrm{PBC}$ & 0.515 & 0.113 & 0.524 & $<0.001 * * *$ & \\
\hline $\mathrm{PN} \Leftarrow \mathrm{SN}$ & 0.407 & 0.085 & 0.432 & $<0.001 * * *$ & \\
\hline PN & & & & & 0.635 \\
\hline $\mathrm{SN} \leftarrow \mathrm{PBC}$ & 0.401 & 0.109 & 0.384 & $<0.001 * * *$ & \\
\hline SN & & & & & 0.147 \\
\hline
\end{tabular}

$$
\text { Note: }{ }^{* *} p<0.001 ; * * p<0.01 ; * p<0.05 ; p<0.1 \text {. }
$$

Habit is, as expected, the most important predictor of the behavior, followed by the intention, which is marginally significant in explaining the behavior. However, an unexpected negative effect of intention on behavior remains. On the second level, the habit is strongly predicted by personal norms, which, at the same time, personal norms also have significantly impact to the intention. The impact of the normative process is, as hypothesized, of significance. Other predictors of the intention, i.e., attitude and social norms do however fail to show significant influence on the intention. In other words, the readiness/will to reduce paper is only significantly predicted by personal the obligation of reducing paper consumption.

Situational influences do not impact the behavior directly. Rather situational constraints impact the behavior indirectly mediated, however not by intentional process, but by normative process, which in turn influences habit. It is also interesting to mention that social norms, such as perceived behavioral control, impact the behavior indirectly, mediated by both personal norms and habit.

Summarizing, it seems that paper consumption behavior begins from appreciation of situational factors, which influences norms, which in turn forms habit. The habit subsequently influences paper 
consumption behavior. In other words, a person who perceived that he/she is able to reduce paper usage is likely the one who feels obliged to do so. The feeling of personal obligation to reduce paper would form habit under stable condition. A person habitually reducing his/her paper consumption associates with the one who reduces his/her paper consumption. Meanwhile, a person with the feeling of personal obligation to reduce paper is more likely the one who is willing to reduce paper consumption, but this does not necessarily associate to the behavior of reducing paper consumption.

Model fit indices depicted in Table 3 indicate an acceptable fit of both measurement and structural models. This implies that the proposed model is supported by the empirical data and able to reproduce the observed variance-covariance matrix.

Table 3. Model fit indices of the measurement and tested structural model $(N=266)$.

\begin{tabular}{|c|c|c|c|}
\hline Index & Acceptable Fit Criteria & Measurement Model & Structural Model \\
\hline$C h i^{2} / d f / p$ & & $124.226 / 57 /<0.001$ & $145.640 / 66 /<0.001$ \\
\hline Ratio of $C h i^{2}$ to $d f$ & $2-5[42-44]$ & 2.1 & 2.4 \\
\hline $\begin{array}{l}\text { CFI } \\
\text { (Comparative Fit Index) }\end{array}$ & $\begin{array}{c}\text { equal to or greater than } \\
0.90[45]\end{array}$ & 0.941 & 0.918 \\
\hline $\begin{array}{l}\text { RMSEA } \\
\text { (Root Mean Square } \\
\text { Error of Approximation) }\end{array}$ & less than or equal to 0.08 & 0.067 & 0.074 \\
\hline
\end{tabular}

\section{Discussions}

This present study aims primarily at understanding underlying variables of paper consumption behavior. Due to exploratory nature of the study, CADM was utilized so that all possible variables are examined and filtered to deliver relevant variables, which explain paper usage behavior. The theoretical model was contrasted with the empirical data using the Structural Equation Modeling. Results indicate that the model receives reasonable support from the empirical data. To some extent, the present study also contributes to test the applicability of CADM in the application domain of paper consumption behavior.

Results also reveal that reducing paper usage behavior is mainly predicted by habitual process, indicating a cognitive lock-in where people do repetitive actions over time. It points out that previous paper consumption interferes with current paper usage behavior. The result is consistent with Klöckner and Blöbaum [33], who argued that the influence of habit should be especially strong for daily behavior, but weak if not irrelevant for investment behavior, such as in Sopha and Klöckner [19], who investigated investment behavior of heating systems. Habit has been found to be dominant in travel mode choice [33], domestic energy consumption [14], and water consumption [46]. As theoretically expected, results also demonstrate that the paper consumption behavior is weakly predicted by intentional process, which normally represents a rational decision-making. The dominance of habit over intentional process may explain why the paper consumption is steadily increasing in spite of PLO program. It indicates that the PLO program may not be perceived as a choice at all so that people consume papers like the way they are used to consume.

It is also interesting to note that, although marginally significant, the negative impact of intention toward behavior indicates that the desire to reduce paper usage does not associate to the actual 
behavior of reducing paper usage. The result is, however, supported by Marechal [47], who confirmed that intention does not always translate into behavior when strong influence of habit exists. Hence, the presence of a strong habit may explain the negative impact. In addition, the strong habit limits the predictive power of $\mathrm{PBC}$, which is found to be insignificant to explain paper consumption behavior.

On the second level, the intention is significantly predicted by personal norms, whereas attitude toward reducing paper consumption, peer pressure, as well as, perceived difficulties to reduce paper usage, fail to show significant impact on the intention. It implies that those who have strong personal norms are, more likely, willing to reduce paper consumption. However, those with high intention do not reduce paper consumption due to habit influence. It is also worth noting that, although the impact of attitude to intention is insignificant, an intention-attitude gap can be observed, in line with Vermeir and Verbeke [36]. People with positive attitudes toward paper usage reduction are corresponding to those with low intentions.

Furthermore, attitude is significantly influenced by both personal norms and $\mathrm{PBC}$, indicating that both the feeling of personal obligation and situational constraint shape the person's feeling whether reducing paper consumption is good or vice versa.

Results also demonstrate habit formation. Before habit is generated, behavior is likely, as expected, to be in line with personal norms. Further, personal norms are related to social norms, as personal norms are obtained during interaction with other people. Although situational influence does not impact behavior directly, it, however, impacts on habitual process mediated by normative process (personal and social norms). The results confirm that habit is dependent on contextual factors. This implies that habit could be changed by altering the circumstances tied to the formation of a habit. On the contrary, stability of the context facilitates stable behavior thereby developing a habit.

Due to the fact that the paper consumption behavior is more habitual, thus, the intention no longer dominates. This implies that policy should not be directed to cognitive-related interventions, rather, it should be focused on breaking habitual behavior. It implies that possible intervention could be worked on contextual change because it increases receptivity towards a given behavior [47]. For example, an aggressive information campaign on the benefits associated to the PLO program unlikely results in paper consumption reduction because the current usage of paper is primarily driven by habitual process, consistent with Verplanken et al. [48]. Within the context of paper consumption, potential intervention could, therefore, be the introduction of printing fees, which is, in general, in line with Alcott [49], who introduced quota and rationing for compensating efficiency gains. However, the change of context is not usually effective in changing habit, particularly for those whose habits have been stable for a long period of time. The intervention would probably be effective if targeting to new students whose previously habits might be perturbed by the change of physical location. When behavior is new to a person, intention influences actual behavior. However, as a person gets more experience over time, in which the behavior occurs more frequently, there would be a shift from consciously-driven behavior toward automatic behavior. It could be argued that intervention, during early stages, should be directed to shape person intention. However, the same intervention would not give the same effect over time as, once the person acts more frequently, habit governs the behavior. Other researchers suggest a combined strategy between contextual changes and individual factors, such as joint use of feedback and social commitment in reducing energy consumption [50]. For individuals with strong personal norms, social commitment, in addition to contextual change, could also be 
introduced. In fact, many empirical studies suggest employing combined strategies for an intervention to be effective [51].

Although the model is successful in explaining the behavior, limitations should be highlighted. First, since the respondents are dominated by students who are in the second year of study and above, the result of this study may differ if new students dominate the sample as new students have just experienced a change of contextual factors, which in turn may have different determinants of paper consumption behavior. Second, the behavior was based on self-report measures, as applied by most studies in environmental psychology [13], instead of objective measures. Although self-report measures were found to be adequate indicators of actual behavior [52], and found to have strong positive correlation with objective measures [53], self-report measures could lead to either overestimation or underestimation. Third, some Cronbach alpha values are below the usual cut-off of 0.7 , even though the measures were adopted from literature, which are both the most reliable and widely used measures. The low value of Cronbach alpha could be due to the use of only two items for measuring each behavioral variable. Thus, more related items should have been added to increase the alpha.

Future potential research could further test the suggested potential interventions to reduce paper consumption. Due to under-representation of first year students in this study, potential research could examine whether or not new students may differ from senior students when it comes to paper consumption. Other future research could also explore on how individual habits spread and, thus, affect the routines of organization.

\section{Acknowledgements}

The author would like to thank to all students who participated in the survey, Anna Maria and Sholeh Ma'mun for editorial assistances, and anonymous reviewers for useful comments.

\section{Conflicts of Interest}

The author declares no conflict of interest.

\section{References}

1. Stephen J. DeCanio. "The efficiency paradox: Bureaucratic and organizational barriers to profitable energy-saving investment." Energy Policy 26 (1988): 441-54.

2. Reinhard Haas, and Peter Biermayr. "The rebound effect for space heating: Empirical evidence from Austria." Energy Policy 28 (2000): 403-10.

3. Abigail J. Sellen, and Richard H. R. Harper. The Myth of the Paperless Office. Cambridge: MIT Press, 2002.

4. Richard York. "Ecological paradoxes: William Stanley Jevons and the paperless office." Human Ecology Review 13 (2006): 143-47.

5. Cees J. H. Midden, Florian G. Kaiser, and Teddy McCalley. "Technology's four roles in understanding individuals' conservation of natural resources." Journal of Social Issues 63 (2007): 155-74. 
6. Thomas Dietz, Paul C. Stern, and Gregory A. Guagnano. "Social structural and social psychological bases of environmental concern." Environment and Behavior 30 (1998): 450-71.

7. Indonesian Environmental Ministry, 2012. Available online: http://www.menlh.go.id/ konservasihutan Indonesia/ (accessed on 10 June 2012).

8. Indonesian Forestry Ministry, 2000. Available online: http://www.dephut.go.id/ (accessed on 10 June 2012).

9. Asosiasi Pulp dan Kertas Indonesia (APKI). Indonesian Pulp and Paper Industry Directory 2005. Jakarta: APKI, 2005.

10. Michael W. Toffel, and Arpad Horvath. "Environmental implications of wireless technologies: News delivery and business meetings." Environmental Science and Technology 38 (2004): 2961-70.

11. Indonesian Ministry of Industry, 2013. Available online: http://agro.kemenperin.go.id/ 1298-Produksi-Kertas-Diproyeksi-Capai-13-Juta-Ton (accessed on 15 May 2013).

12. J. Stanley Black, Paul C. Stern, and Julie T. Elworth. "Personal and contextual influences on household energy adaptations." Journal of Applied Psychology 70 (1985): 3-21.

13. Linda Steg, and Charles Vlek. "Encouraging pro-environmental behavior: An integrative review and research agenda." Journal of Environmental Psychology 29 (2009): 309-17.

14. Wokje Abrahamse, Linda Steg, Charles Vlek, and Talib Rothengatter. "A review of intervention studies aimed at household energy conservation." Journal of Environmental Psychology 25 (2005): 273-91.

15. Charlie Wilson, and Hadi Dowlatabadi. "Models of decision making and residential energy use." Annual Review of Environment and Resources 32 (2007): 169-203.

16. Gerald T. Gardner, and Paul C. Stern. Environmental Problems and Human Behaviour. Boston: Pearson, 2002.

17. Corrado Di Maria, Susana Ferreira, and Emiliya A. Lazarova. "Shedding light on the light bulb puzzle: The role of attitudes and perceptions in the adoption of energy efficient light bulbs." Scottish Journal of Political Economy 57 (2010): 48-67.

18. André Hansla, Amelia Gamble, Asgeir Juliusson, and Tommy Gärling. "Psychological determinants of attitudes towards and willingness to pay for green electricity." Energy Policy 36 (2008): 768-74.

19. Bertha Maya Sopha, and Christian A. Klöckner. "Psychological factors in the diffusion of sustainable technology: A study of Norwegian households' adoption of wood pellet heating." Renewable and Sustainable Energy Reviews 15 (2011): 2756-65.

20. Anders Q. Nyrud, Anders Roos, and Jon Bingen Sande. "Residential bio-energy heating: A study of consumer perceptions of improved woodstoves.” Energy Policy 36 (2008): 3169-76.

21. Wokje Abrahamse, and Linda Steg. "How do socio-demographic and psychological factors relate to households' direct and indirect energy use and savings?" Journal of Economic Psychology 30 (2009): 711-20.

22. Susan M. Macey. "A causal model of the adoption of home heating energy conservation measures." Energy 16 (1991): 621-30.

23. Benjamin Gardner, and Charles Abraham. "Going green? Modeling the impact of environmental concerns and perceptions of transportation alternatives on decision to drive." Journal of Applied Social Psychology 40 (2010): 831-49. 
24. Bas Verplanken, Ian Walker, Adrian Davis, and Michaela Jurasek. "Context change and travel mode choice: Combining the habit discontinuity and self-activation hypotheses." Journal Environmental Psychology 28 (2008): 121-27.

25. Annika M. Nordlund, and Jörgen Garvill. "Effects of values, problem awareness, and personal norm on willingness to reduce personal car use." Journal of Environmental Psychology 23 (2003): 339-47.

26. Anja Peters, Heinz Gutscher, and Roland W. Scholz. "Psychological determinants of fuel consumption of purchased new cars.” Transportation Research Part F 14 (2011): 229-39.

27. Kimberly D. Johns, Kseniya M. Khovanova, and Eric W. Welch. "Fleet conversion in local government: Determinants of driver fuel choice for bi-fuel vehicles." Environment and Behavior 41 (2009): 402-26.

28. Paul C. Stern, Oran R. Young, and Daniel Druckman, eds. Global Environmental Change: Understanding the Human Dimensions. Washington: National Academy Press, 1992.

29. Icek Ajzen. "The theory of planned behavior." Organizational Behavior and Human Decision Process 50 (1991): 179-211.

30. Shalom H. Schwartz. "Normative Influences on Altruism." In Advances in Experimental Social Psychology. Edited by Leonard Berkowitz. New York: Academic Press, 1977, pp. 1-63.

31. Paul C. Stern, Thomas Dietz, Troy Abel, Gregory A. Guagnano, and Linda Kalof. "A Valuebelief-norm theory of support for social movements: The case of environmentalism." Human Ecology Reviews 6 (1999): 81-96.

32. Harry C. Triandis. "Values, Attitudes, and Interpersonal Behavior." In Nebraska Symposium on Motivation. Edited by Herbert E. Howe and Monte M. Page. Lincoln: University of Nebraska Press, 1980.

33. Christian A. Klöckner, and Anke Blöbaum. "A comprehensive action determination model: Toward a broader understanding of ecological behavior using the example of travel mode choice." Journal of Environmental Psychology 30 (2010): 574-86.

34. Sebastian Bamberg, and Guido Möser. "Twenty years after Hines, Hungerford, and Tomera: A new meta-analysis of psycho-social determinants of pro-environmental behavior." Journal of Environmental Psychology 24 (2007): 14-25.

35. Bas Verplanken, Henk Aarts, Ad Van Knippenberg, and Anja Moonen. "Habit versus planned behavior: A field experiment." British Journal of Social Psychology 37 (1998): 111-28.

36. Iris Vermeir, and Wim Verbeke. "Sustainable food consumption: Exploring the consumer attitudebehavioral intention gap." Journal of Agriculture and Environmental Ethics 19 (2006): 169-94.

37. Midori Aoyagi-Usui, Henk Vinken, and Atsuko Kuribayashi. "Pro-environmental attitudes and behaviors: An international comparison." Research in Human Ecology 10 (2003): 23-31.

38. Icek Ajzen. "Residual effects of past on later behavior: Habituation and reasoned action perspectives.” Personality and Social Psychology Review 6 (2002): 107-22.

39. Moez Limayem, Sabine Gabriele Hirt, and Christy M. K. Cheung. "How habit limits the predictive power of intention: The case of information systems continuance." MIS Quarterly 31 (2007): 705-37. 
40. Emily Huddart Kennedy, Thomas M. Beckley, Bonita L. McFarlane, and Solange Nadeau. "Why we don't 'walk the talk': Understanding the environmental values/behavior gap in Canada." Research in Human Ecology 16 (2009): 151-60.

41. Bertha Maya Sopha, Christian A. Klöckner, Even Bjørnstad, and Ellen Matthies. "Literature Research on Energy Behavior: Behavioral Models, Determinants, Indicators, Barriers and Interventions." Enova Project Report, 2011, unpublished.

42. Blair Wheaton, Bengt Muthén, Duan F. Alwin, and Gene F. Summers. "Assessing Reliability and Stability in Panel Models." In Sociological Methodology. Edited by David R. Heise. San Francisco: Jossey-Bass, 1977.

43. Randall E. Schumacker, and Richard G. Lomax. A Beginner's Guide to Structural Equation Modeling, 2nd ed. Mahwah, NJ: Lawrence Erlbaum Associates, 2004.

44. Herbert W. Marsh, and Dennis Hocevar. "Application of confirmatory factor analysis to the study of self-concept: First- and higher order factor models and their invariance across groups." Psychological Bulletin 97 (1985): 562-82.

45. Xitao Fan, Bruce Thompson, and Lin Wang. "Effects of sample size, estimation method, and model specification on structural equation modeling fit indexes." Structural Equation Modeling 6 (1999): 56-83.

46. Gary D. Gregory, and Michael Di Leo. "Repeated behavior and environmental psychology: The role of personal involvement and habit formation in explaining water consumption." Journal of Applied Social Psychology 33 (2006): 1261-96.

47. Kevin Marechal. "Not irrational but habitual: The importance of behavioral lock-in energy consumption.” Ecological Economics 69 (2010): 1104-14.

48. Bas Verplanken, Henk Aarts, and Ad Van Knippenberg. "Habit, information acquisition, and the process of making travel mode choices.” European Journal of Social Psychology 27 (1997): 539-60.

49. Blake Alcott. “Jevon's Paradox.” Ecological Economics 54 (2005): 9-21.

50. Sarah Darby. "The Effectiveness of Feedback on Energy Consumption-A Review for Defra on the Literature on Metering, Billing and Direct Displays.” Oxford University, Environmental Change Institute, UK, 2006. Available online: http://www.eci.ox.ac.uk/research/energy/downloads/ smart-metering-report.pdf (accessed on 5 January 2012).

51. Thomas Dietz, Gerald T. Gardner, Jonathan Giligan, Paul C. Stern, and Michael P. Vandenbergh. "Household actions can provide a behavioral edge to rapidly reduce US carbon emissions." Proceedings of the National Academy of Sciences of the United States of America 106 (2009): 18452-56.

52. Edwin T. Fuj, Michael Hennessy, and James Mak. "An evaluation of the validity and reliability of survey response data on household electricity conservation.” Evaluation Review 9 (1985): 93-104.

53. Agne Suziedelyte, and Meliyanni Johar. "Can you trust survey responses? Evidence using objective health measures.” Economics Letters 121 (2013): 163-66.

(C) 2013 by the author; licensee MDPI, Basel, Switzerland. This article is an open access article distributed under the terms and conditions of the Creative Commons Attribution license (http://creativecommons.org/licenses/by/3.0/). 